\title{
ОСОБЛИВОСТІ КЛІНІЧНОЇ КАРТИНИ ТА АНТРОПОМЕТРИЧНИХ ПОКАЗНИКІВ У ХВОРИХ НА НЕАЛКОГОЛЬНУ ЖИРОВУ ХВОРОБУ ПЕЧІНКИ
}

\author{
๑І. В. Чопей, К. І. Чубірко, Т. І. Гряділь, В. В. Івачевська \\ ДВНЗ «Ужгородський національний університет»
}

РЕЗЮМЕ. Робота присвячена вивченню особливостей клінічної картини неалкогольного стеатозу та стеатогепатиту в пацієнтів з предіабетом та цукровим діабетом (ЦД) 2 типу. Проведено обстеження 117 хворих на неалкогольну жирову хворобу печінки (НАЖХП) та предіабет і ЦД 2 типу. Вивчено поширеність неалкогольного стеатозу та стеатогепатиту у пацієнтів з предіабетом. Доведено, що хворих на НАЖХП та предіабет слід відносити до групи дуже високого кардіоваскулярного ризику (КР). Досліджено особливості вуглеводного та ліпідного обмінів у пацієнтів з НАЖХП на фоні предіабету та ЦД 2 типу.

Матеріал і методи. У роботі відображено результати комплексного обстеження 141 пацієнта з цД 2 типу та предіабетом.

Результати. Провідними симптомами у хворих з НАЖХП є нудота, біль, метеоризм та порушення випорожнень. Достовірно значимі відмінності між пацієнтами I та II груп були виявлені тільки за такими скаргами як метеоризм, загальна слабкість, відчуття гіркоти в ротовій порожнині та нудота.

Висновки. НАЖХП діагностовано у 98,4 \% хворих на ЦД 2 типу, в тому числі стеатоз зустрічався у 54,84 \%, а стеатогепатит - у 45,16\%. У осіб з предіабетом НАЖХП встановлено у 70,5 \%, з них у 85,45 \% - стеатоз та у $14,55 \%$ стеатогепатит $(p<0,05)$. Особливостями клінічної картини НАЖХП є олігосимптомність, коморбідність і переважання диспепсичного синдрому (метеоризм зустрічався у 43,59\%, біль у правому підребер'ї та дискомфорт у черевній порожнині - у 29,91 \% та у 28,21 \% відповідно, запор та відчуття гіркоти в ротовій порожнині - по 21,37 \%).

КлючовІ СлОВА: неалкогольна жирова хвороба печінки; предіабет; цукровий діабет 2 типу.

Вступ. Неалкогольна жирова хвороба печінки (НАЖХП), початковою стадією якої $\epsilon$ стеатоз, який може прогресувати в стеатогепатит, на сьогодні $\epsilon$ найчастішою причиною хронічних захворювань печінки у багатьох розвинених країнах [1]. Дані епідеміологічних досліджень $[15,16]$ підтверджують тенденцію до збільшення захворюваності на НАЖХП у пацієнтів з резистентністю до інсуліну, що виникає на фоні ожиріння, цукрового діабету (ЦД) 2 типу та наявності метаболічного синдрому. Зв'язок між метаболічним синдромом (MC) та НАЖХП настільки сильний, що останню вважають печінковою маніфестацією МС [2-14].

Вищенаведене підтверджує актуальність проблеми, а з огляду на ризики, які зумовлює поєднаний перебіг ЦД 2 типу та НАЖХП, спонукає до розробки ефективної схеми лікування неалкогольного стеатогепатиту та стеатозу на основі вивчення метаболічних порушень. Важливими є розробка диференційних схем лікування НАЖХП у пацієнтів з предіабетом і ЦД 2 типу та оцінка кардіоваскулярного ризику (КР) і поширеності НАЖХП у даної категорії хворих.

Мета дослідження - вивчити особливості клінічного перебігу НАЖХП у хворих на предіабет та ЦД 2 типу.

Матеріал і методи дослідження. У роботі відображено результати комплексного обстеження 141 пацієнта з ЦД 2 типу та предіабетом, які перебували на стаціонарному лікуванні у терапевтичному відділенні К3 «Ужгородська районна лікарня» або звертались амбулаторно на кафедру терапії та сімейної медицини факультету післядипломної освіти та доуніверситетської підготовки ДВНЗ «УжНУ».

Усі хворі, включені в дане дослідження, були поділені на 2 групи: до I групи ввійшли пацієнти 3 предіабетом та НАЖXП (n=55), до II групи - пацієнти з ЦД 2 типу та НАЖХП ( $n=62)$. До III групи (групи контролю) увійшли 30 практично здорових осіб. Достовірної різниці за гендерним і віковим складом виявлено не було ( $p>0,05)$.

Методи дослідження - загальноклінічне обстеження хворих; лабораторні та інструментальні дослідження (загальний аналіз крові з визначенням формули, біохімічні тести, цукор крові натще, глікозильований гемоглобін, ліпідограма, індекс ожиріння печінки, неінвазивна оцінка морфології печінки, електрокардіографія (ЕКГ), тредмілергометрія, ультразвукове дуплексне дослідження екстракраніального відділу сонних артерій, ультразвукова діагностика органів черевної порожнини (УзД ОЧП), в тому числі еластографія печінки, КТ і/або МРТ, методи статистичного аналізу).

Результати й обговорення. Підступність НАЖХП полягає в тому, що частіше перебіг цього захворювання безсимптомний, а будь-які симптоми зі сторони шлунково-кишкого тракту є неспецифічними і не дозволяють диференціювати НАЖХП від інших захворювань. Провідними симптомами у хворих з НАЖХП, за даними деяких авторів, $є$ нудота, біль, метеоризм та порушення випорожнення $[9,14]$. 
Огляди літератури, оригінальні дослідження, погляд на проблему, ювілеї

Аналіз скарг зі сторони шлунково-кишкового тракту виявив, що найчастіше пацієнтів обох груп турбував метеоризм (43,59 \%) (рис. 1$)$.

Загальна слабкість і біль у правому верхньому квадранті живота зустрічались у 29,9 \% пацієнтів, включених у дослідження. Дещо менша кількість хворих скаржились на дискомфорт у черев- ній порожнині $(28,21 \%)$, на запор та відчуття гіркоти в ротовій порожнині - 21,37 \%. На діарею, зниження апетиту та нудоту скаржились відповідно 3,42 \%, 5,13 \% та 10,26 \% пацієнтів відповідно. Підвищення апетиту відмічали 11,11 \% обстежених осіб, а чергування діареї та запорів $11,97 \%$.

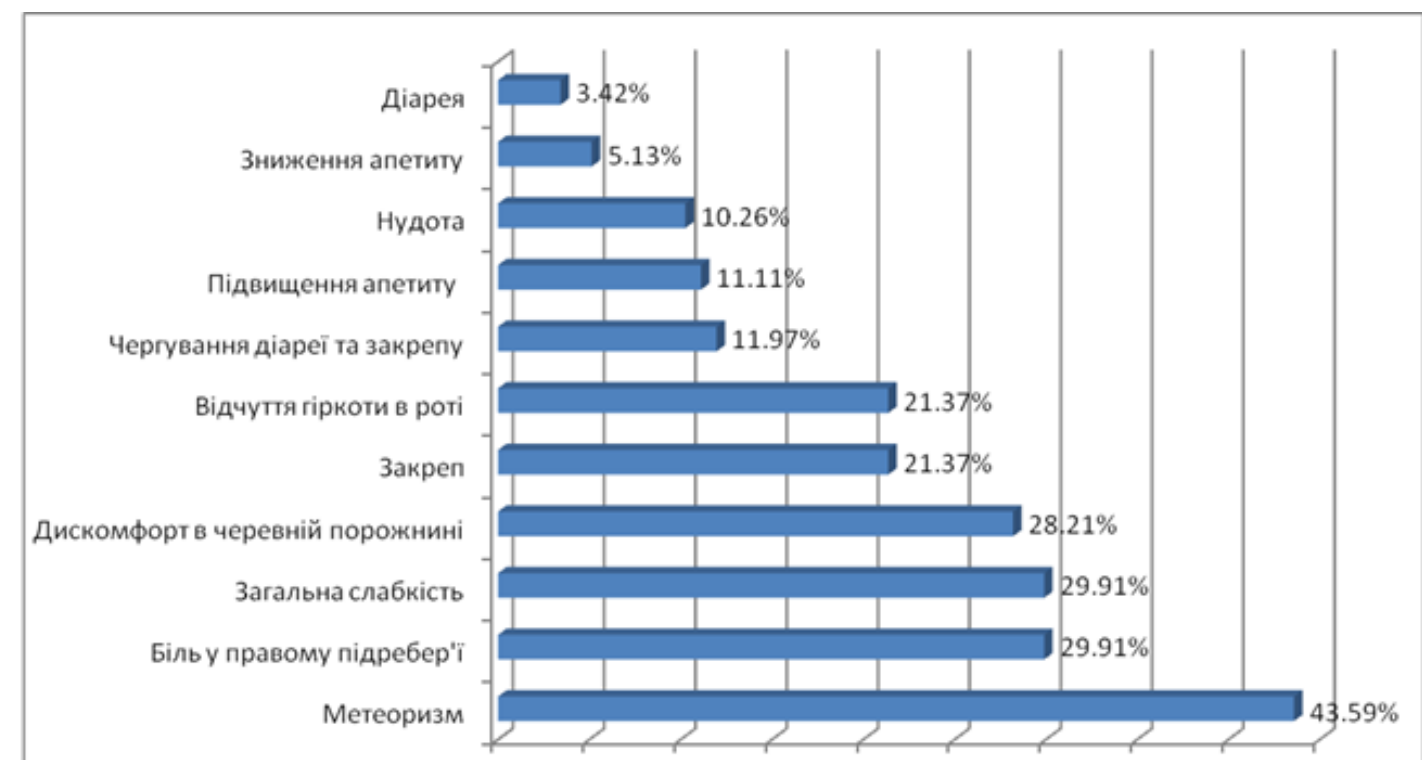

Рис. 1. Розподіл пацієнтів залежно від скарг (\%).

У межах груп розподіл пацієнтів за скаргами був неоднорідним (табл. 1). Достовірно значимі відмінності між пацієнтами I та II груп були вияв- лені тільки за такими скаргами як метеоризм, загальна слабкість, відчуття гіркоти в ротовій порожнині та нудота.

Таблиця 1. Структура скарг зі сторони шлунково-кишкового тракту в обстежених пацієнтів (\%)

\begin{tabular}{|c|c|c|c|c|c|c|}
\hline \multirow{3}{*}{ Скарги з боку ШКТ } & \multicolumn{6}{|c|}{ Групи пацієнтів } \\
\hline & \multirow{2}{*}{$\begin{array}{c}\text { група I } \\
(\mathrm{n}=55)\end{array}$} & \multirow{2}{*}{$\begin{array}{c}\text { група II } \\
(\mathrm{n=62)}\end{array}$} & \multirow{2}{*}{$\begin{array}{c}\text { група III甲 } \\
(n=30)\end{array}$} & \multicolumn{3}{|c|}{$\begin{array}{c}\text { достовірність різниці } \\
\text { показників відповідних груг }\end{array}$} \\
\hline & & & & $\mathrm{pl}-\mathrm{II}$ & $\mathrm{pl}-\mathrm{III}$ & pll-III \\
\hline Зниження апетиту & $2(3,6)$ & $4(6,5)$ & $1(3,3)$ & 0,48 & 0,94 & 0,52 \\
\hline Підвищення апетиту & $4(7,3)$ & $9(14,5)$ & $2(6,7)$ & 0,17 & 0,91 & 0,28 \\
\hline Метеоризм & $18(32,7)$ & $33(53,2)$ & $2(6,7)$ & $0,03 *$ & $<0,01^{*}$ & $<0,01^{*}$ \\
\hline Діарея & $1(1,8)$ & $4(6,5)$ & $0(0)$ & 0,21 & 0,53 & 0,15 \\
\hline Запор & $12(21,8)$ & $13(20,9)$ & $3(10)$ & 0,89 & 0,17 & 0,19 \\
\hline Чергування діареї та запору & $5(9,1)$ & $9(14,5)$ & $1(3,3)$ & 0,40 & 0,32 & 0,11 \\
\hline Відчуття гіркоти в роті & $7(12,7)$ & $18(29,0)$ & $2(6,7)$ & $0,04 *$ & 0,39 & $0,02 *$ \\
\hline Нудота & $1(1,8)$ & $11(17,8)$ & $0(0)$ & $<0,01 *$ & 0,46 & $0,01 *$ \\
\hline $\begin{array}{l}\text { Біль у правому верхньому } \\
\text { квадранті живота }\end{array}$ & $14(25,5)$ & $21(33,9)$ & $0(0)$ & 0,32 & $<0,01 *$ & $<0,01^{*}$ \\
\hline Загальна слабкість & $7(12,7)$ & $29(46,8)$ & $0(0)$ & $<0,01 *$ & $0,04 *$ & $<0,01^{*}$ \\
\hline $\begin{array}{l}\text { Дискомфорт у черевній } \\
\text { порожнині }\end{array}$ & $16(29,1)$ & $17(27,4)$ & $2(6,7)$ & 0,84 & $0,02 *$ & $0,02 *$ \\
\hline
\end{tabular}

Примітки: 1. n - кількість хворих; \% - відсоток пацієнтів від загальної кількості у даній групі; р- достовірність різниці показників відповідних груп;

2. * - статистично вірогідна різниця при порівнянні показників між відповідними групами.

3. $\Theta$ - контрольна група. 
Огляди літератури, оригінальні дослідження, погляд на проблему, ювілеї

При цьому достовірно більша кількість паці$\epsilon$ нтів I групи скаржилися на метеоризм $(p<0,01)$, біль у правому верхньому квадранті живота $(p<0,01)$, загальну слабкість $(p=0,04)$ та дискомфорт у черевній порожнині $(p=0,02)$, порівняно $з$ контрольною групою.

При порівнянні хворих II та контрольної груп вірогідною виявилась різниця кількості пацієнтів з такими скаргами як метеоризм $(p<0,01)$, відчуття гіркоти в роті $(p=0,02)$, нудота $(p=0,01)$, біль у правому верхньому квадранті живота $(p<0,01)$, загальна слабкість $(p<0,01)$ та дискомфорт у черевній порожнині $(p=0,02)$.

Таким чином, особливостями клінічної картини НАЖХП $є$ олігосимптомність, коморбідність та переважання диспепсичного синдрому.

Встановлено, що чоловіки та жінки всіх груп не відрізнялись за зростом ( $>>0,05)$. При цьому маса тіла та індекс маси тіла (IMT) у пацієнтів I і II груп та в осіб контрольної групи вірогідно відрізнялись $(p<0,01)$. Найменша маса тіла, а відтак й IMT, була в осіб групи контролю, найбільша - у пацієнтів з ЦД 2 типу та НАЖХП. Цікаво, що середнє арифметичне IMT, як у чоловіків, так і у жінок з ЦД 2 типу, вказувало на наявність у них ожиріння І ступеня ((33,85 $\pm 0,82)$ та $(32,42 \pm 1,25)$ відповідно), у хворих з предіабетом та НАЖХП - надмірної маси тіла $((27,26 \pm 2,70)$ та $(29,97 \pm 2,47)$ відповідно). В осіб контрольної групи була нормальна маса тіла за показником середнього арифметичного IMT $((24,33 \pm 1,47)$ у чоловіків та $(23,73 \pm 2,31)$ у жінок). Показник абдомінального ожиріння оцінювали за обводом талії (ОТ) та відношенням ОТ до обводу стегна (ОС). Середнє арифметичне ОТ та ОС у пацієнтів з ЦД 2 типу та НАЖХП було вірогідно вищим, ніж у пацієнтів з предіабетом та НАЖХП та осіб контрольної групи $(p<0,01)$. В той час, як середнє арифметичне ОТ у пацієнтів I групи статистично вірогідно перевищувало середнє арифметичне ОТ осіб контрольної групи, середнє арифметичне ОС вірогідно не відрізнялось ( $p=0,07$ у чоловіків та $p=0,94$ у жінок). Середнє арифметичне відношення ОТ до ОС чоловіків та жінок I групи статистично вірогідно не відрізнялось від відповідних показників пацієнтів з II групи ( $p=0,05$ у чоловіків та $p=0,17$ у жінок). Проте середні арифметичні ОТ/ОС як у чоловіків, так і у жінок груп I та II, були вірогідно вищими, ніж середнє арифметичне ОТ/ОС у чоловіків та жінок контрольної групи $(p<0,01)$.

Висновки. НАЖХП діагностовано у $98,4 \%$ хворих на ЦД 2 типу, в тому числі стеатоз зустрічався у $54,84 \%$, а стеатогепатит - у $45,16 \%$. У осі6 з предіабетом НАЖХП встановлено у 70,5 \%, з них у $85,45 \%$ - стеатоз та у $14,55 \%$ - стеатогепатит $(p<0,05)$. Особливостями клінічної картини НАЖХП $\epsilon$ олігосимптомність, коморбідність та переважання диспепсичного синдрому (метеоризм зустрічався у 43,59 \%, біль у правому підребер'ї та дискомфорт у черевній порожнині -у $29,91 \%$ та у 28,21 \% відповідно, запор та відчуття гіркоти в ротовій порожнині - по 21,37 \%).

Аналіз антропометричних даних свідчить не тільки про наявність у пацієнтів основних груп надмірної ваги та ожиріння, а й про переважання саме абдомінального типу ожиріння.

Перспективи подальших досліджень. У плані подальшого дослідження заслуговує на увагу вивчення поширеності неалкогольного стеатозу та стеатогепатиту у пацієнтів з предіабетом, а також КР. 3 іншого боку, вивчення вуглеводного та ліпідного обмінів у пацієнтів з НАЖХП на фоні предіабету та ЦД 2 типу може бути цікавим, особливо в залежності від різних терапевтичних схем.

\section{ЛІТЕРАТУРА}

1. Фадєєнко Г. Д. Коморбідна патологія, що впливає на серцево-судинний ризик у постінфарктних хворих / Г. Д. Фадєєнко, В. А. Чернишов // Український терапевтичний журнал. - 2014. - № 2. - С. 10-20.

2. Бабак О. Я. Лечебная тактика у пациентов с неалкогольной жировой болезнью печени с учетом уровня цитокератина-18 в плазме крови / О. Я. Бабак, Е. А. Лапшина // Сучасна гастроентерологія. - 2016. № 2. - С. 15-20.

3. Оцінка ефективності гепатопротектора Гепа Веда у хворих із патологією печінки / Ю. М. Степанов, Н. Д. Чухрієнко, А. В. Саленко [та ін.] // Гастроентерологія. - 2015. - № 2. - С. 29-32.

4. Хухліна О. С. Стан фіброзування печінки та його наслідки у хворих на неалкогольний стеатогепатит із коморбідним ожирінням та гіпертонічною хворобою у динаміці лікування препаратами Гепадиф, Езетиміб та

Фозиноприл / О. С. Хухліна, О. Є. Мандрик, А. А. Антонів // Нов. мед. и фарм. - 2013. - № 451. - С. 24-26.

5. Чернявский В. В. Жировая болезнь печени как интегральная проблема внутренней медицины / В. В. Чернявский // Новости медицины и фармации. - 2011. № 4. - С. 354 .

6. Паньків В. І. Піоглітазон: роздуми про реальність і перспективи використання / В. І. Паньків // Міжнародний ендокринологічний журнал. - 2012. - № 1. С. 69-73.

7. Коваленко В. М. Калькулятор кардіоваскулярного ризику / В. М. Коваленко // Здоров'я України. - 2010. - № 3 (тематичний номер). - С. 6.

8. Сіренко Ю. М. Гіпертонічна хвороба і артеріальні гіпертензії / Ю. М. Сіренко. - Донецьк, 2011. - 288 с.

9. Колеснікова О. В. Особливості вуглеводного та ліпідного обміну у хворих на неалкогольну жирову 
Огляди літератури, оригінальні дослідження, погляд на проблему, ювілеї

хворобу печінки залежно від ступеня кардіоваскулярного ризику / О. В. Колеснікова, О. Я. Бабак, Т. А. Соломенцева [та ін.] // Сучасна гастроентерологія. - 2013. № 6. - С. 7-12.

10. Уніфікований клінічний протокол «Неалкогольний стеатогепатит» / Н. В. Харченко, М. К. Хобзей, О. М. Ліщишина [та ін.]. - Наказ МОЗ України № 826 від 06.11 .2014$.

11. Шевчук В. В. Зміни оксидантно-протиоксидантного гомеостазу при неалкогольному стеатогепатиті у хворих з метаболічним синдромом / В. В. Шевчук, О.І. Федів // Вісник проблем біології і медицини. 2013. - Вип. 3 (1). - С. 276-279.

12. Лутай М. И. Эффективность статинотерапии: доказательная медицина и реальная клиническая практика / М. И. Лутай // Здоров'я України. Кардіологія. Ревматологія. Кардіохірургія : тематичний номер. 2016. - № 3 (46). - С. 3.

13. Пархоменко О. М. Кардіопротекція при ішемії міокарда. Можливості та перспективи / О. М. Пархоменко // Науково-практична конференція, присвячена 140-річчю від дня народження М. Д. Стражеска. Київ. - 2016.

14. Малышев П. П. Неалкогольная жировая болезнь печени: аспекты диагностики и лечения/П. П. Малышев, К. В. Иванова // Consilium Medicum, Гастроэнтерология. 2010. - № 2. - C. 2.

\section{REFERENCES}

1. Fadieienko, H.D., \& Chernyshov, V.A. (2014). Komorbidna patolohiia, shcho vplyvaie na sertsevosudynnyi ryzyk u postinfarktnykh khvorykh [The comorbid pathology influencing cardiovascular risk in post-arthritis patients]. Ukrainskyi terapevtychnyi zhurnal - Ukrainian Therapeutic Journal, 2, 10-20 [in Ukrainian].

2. Babak, O.Ya., \& Lapshina, E.A. (2016). Lechebnaya taktika u patsyentov s nealkogolnoy zhyrovoy boleznyu pecheni s uchetom urovnya tsytokeratina-18 v plazme krovi [Therapeutic tactics in patients with non-alcoholic fatty liver disease taking into account the level of cytokeratin-18 in blood plasma]. Suchasna hastroenterolohiia - Modern Gastroenterology, 2, 15-20 [in Russian].

3. Stepanov, Yu.M., Chukhrienko, N.D., \& Salenko, A.V. (2015). Otsinka efektyvnosti hepatoprotektora Hepa Veda $u$ khvorykh iz patolohiieiu pechinky [Evaluation of the effectiveness of hepatoprotector Gep Veda in patients with liver pathology]. Hastroenterolohiia - Gastroenterology, 2, 29-32 [in Ukrainian].

4. Hukhlina, O.S., Mandryk, O.E., \& Antoniv, A.A. (2013). Stan fibrozuvannia pechinky ta yoho naslidky u khvorykh na nealkoholnyi steatohepatyt iz komorbidnym ozhyrinniam ta hipertonichnoiu khvoroboiu u dynamitsi likuvannia preparatamy Hepadyf, Ezetymib ta Fozynopryl [The state of liver fibrosis and its consequences in patients with non-alcoholic steatohepatitis with comorbid obesity and hypertension in the dynamics of treatment with the drugs Hepadif, Ezetimib and Phosinopril]. Novosti meditsiny $i$ farmatsii - News of Medicine and Pharmacy, 451, 24-26 [in Ukrainian].

5. Chernyavskiy, V.V. (2011). Zhirovaya bolezn pecheni kak integralnaya problema vnutrenney meditsiny [Fatty
15. Effect of a 12-month intensive lifestyle intervention on hepatic steatosis in adults with type 2 diabetes / M. Lazo, S. Solga, A. Horska [et al.] // Diabetes Care. - 2010. - Vol. 33. - P. 2156-2163

16. Exercise and non-alcoholic fatty liver disease: a systematic review and meta-analysis / S. E. Keating, D. A. Hackett, J. George [et al.] // J. Hepatol. - 2012. No. 57. - P. 157-166.

17. Systematic review: the epidemiology and natural history of non-alcoholic fatty liver disease and nonalcoholic steatohepatitis in adults / G. Vernon, A. Baranova, Z. M. Younossi // Aliment. Pharmacol. Ther. - 2011. Vol. 34. - P. 274-285.

18. A meta-analysis of randomized trials for the treatment of nonalcoholic fatty liver disease / G. Musso, R. Gambino, M. Cassader [et al.] // Hepatology. - 2010. Vol. 52. - P. 79-104.

19. Ratziu V. A proposal for current and future therapeutic strategies for NASH: EASL Special Conference "NAFLD/NASH and Related Metabolic Disease" Bologna, Italy / V. Ratziu // Program and Abstracts. - 2009. - P. 29.

20. Treatment of atherogenic liver based on the pathogenesis of nonalcoholic fatty liver disease: a novel approach to reduce cardiovascular risk? / M. Maurantonio, S. Ballestri, M. R Odoardi [et al.] // Arch. Med. Res. - 2011. No. 42. - P. 337-353.

liver disease as an integral problem of internal medicine]. Novosti meditsiny i farmatsii - News of Medicine and Pharmacy, 4, 354 [in Russian].

6. Pankiv, V.I. (2012). Piohlitazon: rozdumy pro realnist i perspektyvy vykorystannia [Pioglitazone: Reflections on the reality and perspectives of use]. Mizhnarodnyi endokrynolohichnyi zhurnal - International Endocrinology Journal, 1, 69-73 [in Ukrainian].

7. Kovalenko, V.M. (2010). Kalkuliator kardiovaskuliarnoho ryzyku [Cardiovascular risk calculator]. Zdorovia Ukrainy - Health of Ukraine, 3, 6 [in Ukrainian].

8. Sirenko, Yu.M. (2011). Hipertonichna khvoroba i arterialni hipertenzii [Hypertonic disease and arterial hypertension]. Donetsk [in Ukrainian].

9. Kolesnikova, O.V., Babak, O.Ya., \& Solomenseva, T.A. (2013). Osoblyvosti vuhlevodnoho ta lipidnoho obminu u khvorykh na nealkoholnu zhyrovu khvorobu pechinky zalezhno vid stupenia kardiovaskuliarnoho ryzyku [Features of carbohydrate and lipid metabolism in patients with nonalcoholic fatty liver disease depending on the degree of cardiovascular risk]. Suchasna hastroenterolohiia Modern Gastroenterology, 6, 7-12 [in Ukrainian].

10. Kharchenko, N.V., Khobzei, M.K., \& Lishchyshyna, A.M. (2014). Unifikovanyi klinichnyi protokol "Nealkoholnyi steatohepatyt" [Unified clinical protocol "Non-alcoholic steatohepatitis"]. Nakaz MOZ Ukrainy № 826 - The Order of the Ministry of Health of Ukraine No. 826 [in Ukrainian].

11. Shevchuk, V.V., \& Fediv, O.I. (2013). Zminy oksydantno-protyoksydantnoho homeostazu pry nealkoholnomu steatohepatyti u khvorykh z metabolichnym syndromom [Changes of oxidant-antioxidant homeostasis in non-alco- 
Огляди літератури, оригінальні дослідження, погляд на проблему, ювілеї

holic steatohepatitis in patients with metabolic syndrome]. Visnyk problem biolohii i medytsyny - Bulletin of Biological and Medical Problems, 3 (1), 276-279 [in Ukrainian].

12. Lutay, M.I. (2016). Effektivnost statinoterapii: dokazatelnaya meditsyna i realnaya klinicheskaya praktika [The efficacy of statin therapy: evidence-based medicine and real clinical practice]. Zdorovia Ukrainy. Kardiolohiia. Revmatolohiia. Kardiokhirurhiia - Health of Ukraine. Cardiology. Rheumatology Cardiac Surgery, 3 (46), 3 [in Russian].

13. Parkhomenko, O.M. (2016). Kardioprotektsiia pry ishemii miokarda. Mozhlyvosti ta perspektyvy [Cardiprotection at ischemia of the myocardium. Opportunities and prospects]. Naukovo-praktychna konferentsiia, prysviachena 140-richchiu vid dnia narodzhennia M. D. StrazheskaScientific-Practical Conference devoted to the 140th anniversary of the birth of M. D. Strazhesko [in Ukrainian].

14. Malyshev, P.P., \& Ivanov, K. (2010). Nealkogolnaya zhyrovaya bolezn pecheni: aspekty disgnostiki i lecheniya [Non-alcoholic fatty liver disease: aspects of diagnosis and treatment]. Sonsilium Medicum, Gastroenterologiya Sonsilium Medicum, Gastroenterology, 2, 2 [in Russian].
15. Lazo, M., Solga, S., \& Horska, A. (2010). Effect of a 12-month intensive lifestyle intervention on hepatic steatosis in adults with type 2 diabetes. Diabetes Care, 33, 2156-2163.

16. Keating, S.E., Hackett, D.A., \& George, J. (2012). Exercise and non-alcoholic fatty liver disease: a systematic review and meta-analysis. J. Hepatol., 57, 157-166.

17. Vernon, G., Baranova, A., \& Younossi, Z.M. (2011). Systematic review: the epidemiology and natural history of non-alcoholic fatty liver disease and nonalcoholic steatohepatitis in adults. Aliment. Pharmacol. Ther., 34, 274-285.

18. Musso, G., Gambino, R., \& Cassader, M. (2010). A meta-analysis of randomized trials for the treatment of nonalcoholic fatty liver disease. Hepatology, 52, 79-104.

19. Ratziu, V. (2009). A proposal for current and future therapeutic strategies for NASH: EASL Special Conference "NAFLD/NASH and Related Metabolic Disease" Bologna, Italy. Program and Abstracts, 29.

20. Maurantonio, M., Ballestri, S., \& Odoardi, M.R. (2011). Treatment of atherogenic liver based on the pathogenesis of nonalcoholic fatty liver disease: a novel approach to reduce cardiovascular risk? Arch. Med. Res., 42, 337-353.

\title{
ОСОБЕННОСТИ КЛИНИЧЕСКОЙ КАРТИНЫ И АНТРОПОМЕТРИЧЕСКИХ ПОКАЗАТЕЛЕЙ У БОЛЬНЫХ НЕАЛКОГОЛЬНОЙ ЖИРОВОЙ БОЛЕЗНЬЮ ПЕЧЕНИ
}

\author{
ОИ. В. Чопей, К. И. Чубирко, Т. И. Грядиль, В. В. Ивачевская \\ ВГУз «Ужгородский национальный университет»
}

РЕЗЮМЕ. Работа посвящена изучению особенностей клинической картины неалкогольного стеатоза и стеатогепатита у пациентов с предиабетом и сахарным диабетом (СД) 2 типа. Проведено обследование 117 больных на НАЖБП и предиабет и СД 2 типа. Изучены распространенность неалкогольного стеатоза и стеатогепатита у пациентов с предиабетом. Доказано, что больных НАЖБП и предиабет следует относить к группе очень высокого кардиоваскулярного риска (КР). Исследованы особенности углеводного и липидного обменов у пациентов с НАЖБП на фоне предиабета и СД 2 типа.

Материал и методы. Данная работа отражает результаты комплексного обследования 141 пациента с СД 2 типа и предиабетом.

Результаты. Ведущими симптомами у больных НАЖБП являются тошнота, боль, метеоризм и нарушение стула. Достоверно значимые различия между пациентами I и II групп были обнаружены только по таким жалобам как метеоризм, общая слабость, ощущение горечи во рту и тошнота.

Выводы. НАЖБП диагностирована у 98,4 \% больных СД 2 типа, в том числе стеатоз встречался у 54,84 \%, а стеатогепатит - у 45,16 \%. У лиц с предиабетом НАЖБП установлена в 70,5 \%, из них у 85,45 \% - стеатоз и у 14,55 стеатогепатит $(p<0,05)$. Особенностями клинической картины НАЖХП являются олигосимптомность, коморбидность и преобладание диспепсического синдрома (метеоризм встречался у 43,59 \%, боль в правом подреберье и дискомфорт в брюшной полости - у 29,91 \% и у 28,21 \% соответственно, запор и ощущение горечи в ротовой полости - по 21,37\%).

КЛЮЧЕВЫЕ СЛОВА: неалкогольная жировая болезнь печени; предиабет; сахарный диабет 2 типа.

\section{FEATURES OF THE CLINICAL PICTURE AND ANTHROPOMETRIC INDICES IN PATIENTS WITH NON-ALCOHOLIC FATTY LIVER DISEASE}

\section{@I. V. Chopey, K. I. Chubyrko, T. I. Griadil, V. V. Ivachevska \\ State Higher Education Establishment "Uzhhorod National University"}

SUMMARY. The work is devoted to the study of the features of the clinical picture of nonalcoholic steatosis and steatohepatitis in patients with pre-diabetes and type 2 diabetes mellitus (DM). A survey of 117 patients with a background of NADH and pre-diabetes and type 2 diabetes was performed. The prevalence of non-alcoholic steatosis and steatohepatitis in patients with pre-diabetes was studied. It has been shown that patients with NAGHP and pre- 
Огляди літератури, оригінальні дослідження, погляд на проблему, ювілеї

diabetes should be classified as very high cardiovascular risk (CD). The peculiarities of carbohydrate and lipid metabolism in patients with NADH on the background of pre-diabetes and type 2 diabetes were studied.

Material and Methods. This work reflects the results of a comprehensive survey of 141 patients with type 2 diabetes and pre-diabetes.

Results. The leading symptoms in patients with NADH are nausea, pain, flatulence and stomach upsets. Significant differences between patients in groups I and II were detected only with complaints such as: flatulence, general weakness, sense of bitterness in the oral cavity and nausea.

Conclusions NSCLC was diagnosed in $98.4 \%$ of patients with type 2 diabetes, including steatosis in $54.84 \%$, and steatohepatitis in $45.16 \%$. In persons with pre-diabetic NADH, $70.5 \%$ were established, of which $85.45 \%$ were steatosis and $14.55 \%$ were steatohepatitis $(p<0.05)$. The features of the clinical picture of NADH are oligosymptomy, comorbidity and the predominance of dyspeptic syndrome (flatulence was found in $43.59 \%$, pain in the right hypochondrium and discomfort in the abdominal cavity $-29.91 \%$ and $28.21 \%$ respectively, and a feeling of bitterness in the oral cavity - by $21.37 \%)$.

KEY WORDS: non-alcoholic fatty liver disease; pre-diabet; type 2 diabetes mellitus.

Отримано 22.02.2018 